\title{
Commentary: A plea for a donor CT!
}

\author{
Konrad Hoetzenecker, MD, PhD
}

From the Department of Thoracic Surgery, Medical University of Vienna, Vienna, Austria.

Disclosures: Author has nothing to disclose with regard to commercial support.

Received for publication Dec 14, 2018; accepted for publication Dec 14, 2018; available ahead of print Jan 31, 2019.

Address for reprints: Konrad Hoetzenecker, MD, PhD, Department of Thoracic Surgery, Medical University of

Vienna, Waehringer Guertel 18-20, 1090 Vienna, Austria (E-mail: konrad.hoetzenecker@meduniwien.ac.at).

J Thorac Cardiovasc Surg 2019;157:1720-1

$0022-5223 / \$ 36.00$

Copyright (c) 2018 by The American Association for Thoracic Surgery

https://doi.org/10.1016/j.jtcvs.2018.12.039

I read with great interest the article published by Gauthier and colleagues in the latest issue of the Journal. This excellent work from the St. Louis group highlights the importance of donor CT scans in lung transplantation. ${ }^{1}$

In most donor reports, information on the functional quality of lungs is limited to gas exchange parameters, a bronchoscopy report, and a chest radiograph. Available data often make it difficult to define the true organ quality and to decide on sending out a procurement team. For example, the interpretation of chest radiographs is highly subjective and atelectasis of the lower lobes can be easily mistaken for pneumonic changes. ${ }^{2}$ In addition, poor gas exchange does not automatically define marginal lungs. Impaired blood gases can merely be a result of improper ventilation, mucus plugs, or substantial dorsobasal parenchymal atelectasis (commonly found in donors with a history of several days of intubation). Imagine a 65-year-old donor with a moderate smoking history of 30 pack-years and reported blood gases of $210 \mathrm{mmHg} \mathrm{pO}_{2}$ and $49 \mathrm{mmHg} \mathrm{pCO}_{2}$ at 1.0 inspired oxygen fraction. In such donors, a CT scan ruling out incipient emphysema would be extremely useful.

Organ procurement costs are high. According to a recent article by Chapman and colleagues, ${ }^{3}$ a hospital recovery in the United States costs on average $\$ 35,000$. On the other hand, the cost of a CT scan is in the range of $\$ 1000$. Gauthier and colleagues ${ }^{1}$ described a $15 \%$ chance of detecting structural lung disease in their patient cohort. Extrapolating this $15 \%$ chance to the general donor pool, the implementation of routine donor CT scans would be highly cost-effective from a health economics point of view.

A simple chest radiographic image is insufficient to rule out structural lung disease. The article by Gauthier and colleagues ${ }^{1}$ once more highlights the poor diagnostic yield of chest radiographic images. In a total of 177 donors, 19 had evidence of significant structural lung disease; however, only 2 of these cases were identified by chest radiographic images.

And there are several other arguments in favor of routine donor CTs: CT scans can detect anatomic variants/ abnormalities in advance, precluding a donor lung from

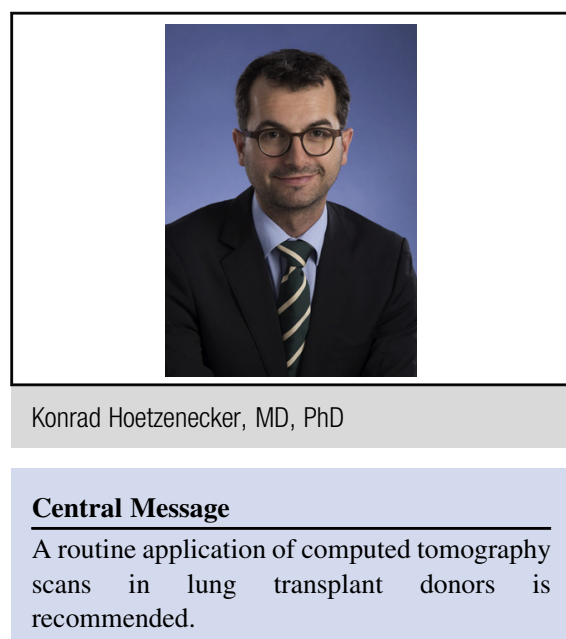

See Article page 1711.

transplantation. In addition, height, width, and depth of donor lungs can be easily measured. Currently, size matching is based on height/weight of the recipient and donor, predicted and real total lung capacity, as well as the recipient's underlying disease. ${ }^{4}$ Including CT-based measurements of chest dimensions could be especially useful for difficult size matches such as in lobar transplantations or pediatric recipients. ${ }^{5,6}$

I would also like to add a word of caution: In the vast majority, donor CT scans also show nonspecific changes such as ground glass opacities or small inflammatory lesions. These changes could mislead less-experienced centers and liberal use of donor CTs might unintentionally decrease lung utilization rates.

In conclusion, there are numerous arguments for but hardly any argument against donor CT scans. A routine application in every donor is recommended to allow better judgment on donor organ quality.

\section{References}

1. Gauthier JM, Bierhals AJ, Liu J, Balsara KR, Frederiksen C, Gremminger E, et al. Chest computed tomography imaging improves potential lung donor assessment. J Thorac Cardiovasc Surg. 2019;157:1711-8.e1.

2. Bozovic G, Adlercreutz C, Hoglund P, Bjorkman-Burtscher I, Reinstrup P, Ingemansson $\mathrm{R}$, et al. Imaging of the lungs in organ donors and its clinical relevance: a retrospective analysis. J Thorac Imaging. 2017;32:107-14.

3. Doyle M, Subramanian V, Vachharajani N, Collins K, Wellen JR, Stahlschmidt E, et al. Organ donor recovery performed at an organ procurement organizationbased facility is an effective way to minimize organ recovery costs and increase organ yield. J Am Coll Surg. 2016;222:591-600.

4. Mason DP, Batizy LH, Wu J, Nowicki ER, Murthy SC, McNeill AM, et al. Matching donor to recipient in lung transplantation: how much does size matter? J Thorac Cardiovasc Surg. 2009;137:1234-40.e1231. 
5. Chen F, Fujinaga T, Shoji T, Yamada T, Nakajima D, Sakamoto J, et al. Perioperative assessment of oversized lobar graft downsizing in living-donor lobar lung transplantation using three-dimensional computed tomographic volumetry. Transpl Int. 2010;23:e41-4.
6. Konheim JA, Kon ZN, Pasrija C, Luo Q, Sanchez PG, Garcia JP, et al. Predictive equations for lung volumes from computed tomography for size matching in pulmonary transplantation. J Thorac Cardiovasc Surg. 2016; 151:1163-9.e1161. 